\title{
Identidades migrantes, fronteira e cidadania.
}

\author{
Prof. Dr. Gabriel O. Alvarez
}

PPGAS/FCS/UFG

\begin{abstract}
Resumo
O trabalho se apóia numa pesquisa de campo extensiva que visitou 14 cidades localizadas nas fronteiras do Brasil com os países do Mercosul. Ao longo do trabalho se analisa os diferentes tipos de migrantes e a dinâmica das identidades, (estigmatizadas, mimetizadas ou invocadas). A pesquisa abordou diferentes tipos de migrantes: os estrangeiros, os que realizam migração pendular e aqueles migrantes de retorno. A fronteira como locus de pesquisa permite também analisar diferentes dimensões analíticas: internacional, transnacional, translocal e regional. $\mathrm{O}$ trabalho analisa também as percepções e expectativas destes trabalhadores migrantes sobre o processo de integração regional do Mercosul $^{1}$.
\end{abstract}

Palavras-chave: migrantes, identidades, Mercosul

\section{Introdução}

Ao longo da pesquisa foram realizadas mais de 70 entrevistas e observação direta nas 14 localidades visitadas na fronteira do Brasil com os países do Mercosul. Neste contexto de fronteira analisamos como diferentes tipos de migrantes invocam ou mimetizam suas identidades. Cardoso de Oliveira (1976) tinha assinalado o duplo caráter das identidades, como construção ideológica e como posição na estrutura social. Barth (2000) com sua perspectiva contrastiva chamou a atenção para o caráter gerativo das identidades como limite que modela a interação entre grupos, como forma de organização social. Wolf (1994) nas suas análises sobre o sistema mundial assinala que o mercado ordena relações sociais, construí um sistema segmentado étnicamente e hierarquicamente ordenado. Frente as implicação das identidades para o acesso à realização dos direitos os indivíduos invocam, mimetizam ou

1 A pesquisa foi realiza com financiamento da Secretaria da Previdência Social, do Ministério da Previdência Social/BR. Os pontos de vista apresentados no texto não representam o ponto de vista do Ministério e são de responsabilidade do autor. 
estigmatizam as identidades ao serem interpelados desde as diferentes situações observadas nas fronteiras.

\section{Fronteiras}

As fronteiras, com suas ambigüidades e particularidades, são um cenário privilegiado para pensar os rumos do processo de integração do Mercosul. A região de fronteira é especialmente sensível ao processo de integração. A fronteira internacional, que teve um lugar privilegiado para a construção da idéia de nação no passado, transforma-se em um cenário igualmente relevante para a construção do Mercosul. Se o processo de integração emperra nas fronteiras, dificilmente alcançará um estagio mais profundo.

As ambigüidades deste espaço social decorrem, em parte, da própria polissemia do termo, pode ser a fronteira como limite, como linha imaginada ou a fronteira como frente de população em movimento. Os migrantes podem realizar uma migração para estabelecer-se definitivamente no país vizinho, ou podem cruzar periodicamente, morando de um lado desta linha e trabalhando no outro. As fronteiras como limites que demarcam a aplicação de políticas sociais se apresentam como um terreno especialmente problemático no processo de integração, como se verá na análise dos dados empíricos.

Fronteiras como limites internacionais, são linhas imaginarias que separam o território de diferentes países soberanos. Apesar do seu caráter imaginário, apresentam suas particularidades e são frutos de um processo histórico modelado pelas geopolíticas de construção dos estados nacionais. As divisórias de águas ou outros acidentes naturais podem servir como limites que fazem o traçado da fronteira mais evidente. A tendência a fixar as fronteiras de acordo a limites naturais tinha por propósito naturalizar as fronteiras nacionais. Nos casos das fronteiras secas, a sinalização com marcos aparece como um índice de onde passaria esta fronteira como linha imaginaria. As fronteiras secas, verdadeiras linhas imaginarias apresentam, com sua porosidade, características diferentes das fronteiras baseadas em divisórias de água.

As fronteiras apresentam uma dinâmica social particular que entrelaça a população de ambos os lados em uma relação translocal. Esta dinâmica foi assinalada como transfronteira por Marcano (1996). De uma ou outra forma a situação transfronteriça esta contemplada pelas legislações sobre área de fronteira e sua dinâmica varia de acordo as particularidades. Devemos ressaltar que a transfronteira tem uma dinâmica própria, translocal que é diferente da internacional, definida ao nível das capitais e negociações entre governos centrais, ou seja, a nível internacional. Estás características trans-locais fazem-se mais evidentes no caso das 
cidades formadas ao longo da linha da fronteira, "cidades gêmeas" que em realidade se configuram como uma cidade governada por dois estados.

Pensar a fronteira a partir dos trabalhadores migrantes nos remete a outro dos sentidos, fronteira como frente de expansão. Neste sentido se relaciona com os fluxos de população e com as migrações na fronteira interna. Este sentido do termo fronteira também foi utilizado para referir-se a uma forma de organização social, caracterizada pela mítica de pioneiros, em um ambiente legal frouxo ou ambíguo, associado a uma terra promissora, cheia de oportunidades. Fronteira no sentido de válvula de escape para as tensões nos núcleos mais antigos, consolidados e com um mercado de trabalho saturado. Neste contexto, a fronteira opera como motor ideológico que impulsiona a migração e a colonização de um território vazio e com fraca presença do estado. Velho (1976) ao analisar camponeses na fronteira norte do Brasil, assinala a valorização da autonomia e o distanciamento do estado, enxergado por estes camponeses como a "besta fera".

Na prática este território de fronteira nunca esteve vazio. Cardoso de Oliveira (1996) analisou a dinâmica produzida pelo encontro das frentes de expansão da sociedade nacional e as populações nativas. Cardoso de Oliveira acunhou o termo fricção inter-étnica para dar conta da relação contraditória entre o mundo dos brancos e o mundo dos índios. Na estrutura social da região, a divisão entre classes sociais, envolvia outra divisão mais profunda, de caráter étnico. Parte desta população indígena, estigmatizada, renuncia a sua identidade étnica e assume a identidade de caboclo (no norte), ou bugre (no sul). Estas populações ficaram no pior dos mundos, renunciaram ao mundo do índio, mais não foram incluídas no mundo do branco (Cardoso de Oliveira 1996). As identidades, como assinala o autor, tem um duplo caráter, como construção ideológica e como posição na estrutura social. As identidades operam como bússolas que orientam relações sociais (Cardoso de Oliveira 1976). Este tema nos coloca frente ao liminar entre a interação e a discriminação, fatos que não são sinônimos. A lógica das identidades tem que ser analisada à luz da estrutura social contraditória, apesar dos ideais de igualdades. Neste sentido, um dos aportes relevantes desta abordagem é a consideração das identidades como fronteiras étnicas, como limites que tem um importante papel na organização da interação entre os grupos.

Em contextos de fronteira as identidades podem operar como fator de etnicidade. Neste sentido as identidades orientam relações sociais e no caso de populações migrantes que se estruturam como minoria étnica no sistema interétnico podem apresentar uma dinâmica de fricção. As identidades, por outro lado, tem um núcleo duro, ancorado na tradição cultural, que recria diferentes subjetividades. 
Wolf (2003) realizou um estudo comparativo sobre duas pequenas vilas nos Alpes, uma delas germânica e a outra românica. Estas duas cidades, com uma população similar e enfrentando as mesmas condições ecológicas seguiram rumos diferentes. Este estudo clássico chama a atenção para a relação entre a realidade observada localmente nos estudos de comunidade e o nível nacional que determina os rumos da realidade observada localmente. Wolf introduziu a discussão dos múltiplos níveis de determinação que operam sobre as realidades observadas localmente e chamou a atenção para fatores como o mercado, que modelam o ordenamento das relaciones sociais. Wolf (1994) descreve o mercado mundial como uma estrutura segmentada etnicamente e hierarquicamente ordenada. A segmentação étnica está relacionada também a estes ordenamentos da força de trabalho produzidos pelos fluxos do comércio mundial. O mercado cria vida social por e para o capital.

Fronteiras também podem ser conceituadas como corredores de compressão de espaço-tempo que conectam espaços atravessando as distâncias. Fluxos de comércio, de pessoas, de dinheiro, símbolos e ideologias criam corredores de compressão do espaço-tempo (Apadurai 1994, Harvey 1993, Ribeiro 1994, 1997, 1998). Estas fronteiras transnacionais aparecem como corredores transnacionais que põem em xeque a lógica das identidades. As fronteiras analisadas neste trabalho apresentam enclaves comerciais, onde a lógica translocal se articula com a lógica transnacional.

Finalmente, como assinalou Canclini (1997), as fronteiras são paradoxalmente um cenário privilegiado de hibridação cultural e ao mesmo tempo lugar de controle. Um controle que se estabelece pelos governos centrais no intento de ordenar o fluxo que as atravessa. Nestes casos os controles de fronteira podem coincidir com o limite internacional ou podem estar localizados em qualquer parte do território. Se a fronteira é imaginada como lugar de controle, a integração, no imaginário, tem sido associada com o levantamento de fronteiras. Em princípio, a integração poderia reforçar os controles nas fronteiras extra-bloco e relaxar os controles nas fronteiras intra-bloco, a exemplo da União Européia.

Estes diversos sentidos de fronteira se entrelaçam nas situações empíricas observadas ao longo da pesquisa. As situações variam de acordo com as características das diversas localidades visitadas. As dificuldades não são as mesmas nas cidades de maior porte que nas cidades pequenas; nas que tem um perfil voltado para os serviços e as que têm um perfil voltado para o setor agrícola. Ainda é importante ressaltar as diferenças entre os municípios com latifúndios mecanizados e uma população eminentemente urbana, que contrata com a situação de municípios com uma estrutura agrária apoiada na pequena propriedade e com uma parcela importante de população rural. 
Ao focar a pesquisa nos trabalhadores migrantes enxergamos uma sociedade fluida, em movimento. Contrariando os modelos clássicos de sociedade como conjunto estável os grupos analisados apresentam uma alta mobilidade. Estes migrantes criam fluxos de pessoas, mercadorias, símbolos, e podem ser enxergada como uma fronteira em movimento, uma população mobilizada por um sentimento de pioneirismo.

A fronteira como sociedade em movimento, rara vez coincide ou respeita a fronteira como limite. Isto implica que este fluxo de migrantes, que avança para a fronteira como limite, com freqüência a atravessa, criando fluxos de migração internacional. Estes fluxos, de migrantes para países vizinhos pode ser reversível. Muitos destes migrantes podem voltar para o país de origem quando perdem suas capacidades laborais, o enfrentam crises que inviabilizam sua permanência no país hospedeiro.

Por outro lado, a fronteira como limite, e as diferenças de condições "do outro lado" motivam a uma importante parcela da população a trabalhar do outro lado da fronteira. Este fenômeno está relacionado com cidades que pela sua participação no comércio e pelos migrantes a ele vinculados se transformaram em verdadeiros enclaves transnacionais nas fronteiras do Mercosul.

Trabalhar com os trabalhadores migrantes permitirá que ao longo da apresentação dos dados a geração de uma tipologia que de conta da dinâmica situação enfrentada pelos migrantes. Migrantes no plural, uma vez que inclui tanto os migrantes internos como os estrangeiros; tanto rurais como urbanos; tanto aqueles que encararam a migração como uma viagem definitiva, como aqueles que retornam; ou ainda aqueles que realizam uma migração pendular, atravessando cotidianamente as fronteiras. Qual é a situação destes migrantes, quantos são e como podem ser contemplados pelas políticas do bloco são alguns dos desafios enfrentados neste trabalho.

\section{Tipologia dos trabalhadores migrantes nas fronteiras de Brasil com o}

\section{Mercosul}

O propósito desta pesquisa foi a elaboração de um perfil dos trabalhadores na área de fronteira com o Mercosul, assim como a forma de inclusão destes nas políticas sociais dos países fronteiriços, em particular nos sistemas previdenciário. Este propósito responde á necessidade de analisar a pertinência e suficiência das atuais políticas previdenciárias, bem como de elencar propostas de aperfeiçoamento e reorientação da atual política. 
A partir do trabalho de campo e da análise dos dados quantitativos, elaboramos uma tipologia dos trabalhadores migrantes das áreas de fronteira. Esta tipologia levou em conta a trajetória laboral, descrição das atividades, características dos deslocamentos, assim como a forma de inclusão social destes nos sistemas previdenciários dos países fronteiriços.

Ao longo da pesquisa identificamos diversos tipos de trabalhadores migrantes, observamos as dificuldades no acesso aos mecanismos de seguridade social e, com as limitações dos dados quantitativos, assinalamos quantos trabalhadores estão protegidos por algum sistema previdenciário dos países fronteiriços, e quantos necessitarão de uma ação inclusiva.

A análise da situação social nos diferentes municípios visitados permite a identificação de três tipos de situações relacionadas com os trabalhadores que migram nas fronteiras do Brasil com os países do Mercosul. Estes três tipos de situações são: os migrantes dos países vizinhos; os migrantes brasileiros de retorno e, finalmente os que realizam migração pendular.

De certa forma estes tipos operam como identidades em diversos sentidos: são geradas na interação no interior de um sistema de identidades; não se relacionam com alguma essência; operam como um limite, que pode ser transposto ao longo do percurso de vida. Assim como as identidades, tem uma dupla natureza, como representação são uma construção ideológica, mas também remetem a uma posição na estrutura social. Como as identidades, estes tipos operam como bússolas que ordenam as relações sociais (Barth 2000, Cardoso de Oliveira 1976, 1996).

Assim como nas identidades, as pessoas têm certo limite de manipulação destas identidades atribuídas por terceiros. Cabe destacar duas estratégias polares de manipulação destas identidades. Por um lado o mimetismo, para passarem despercebidos, por outro a carnavalização das formas, a atuação performática das identidades reforçada por símbolos. O mimetismo como estratégia na procura de apagar os diacríticos de uma identidade estigmatizada. A carnavalização, pelo contrario, orienta as relações sociais, dividindo a partir da invocação de um antagonismo entre identidades (Cardoso de Oliveira 1976, Santos 1995).

Em linhas gerais, nesta fronteira os migrantes internacionais constituem uma pequena parcela da população nas cidades visitadas; os migrantes de retorno, por vezes constituem um grupo mais numeroso que os migrantes internacionais; finalmente, os que realizam migração pendular, principalmente nos municípios relacionados com o comércio, constituem o terceiro grupo, mais numerosos e com cobertura previdenciária mais precária. 
Estes três tipos de migrantes e suas identidades associadas operam num contexto onde os grupos majoritários estão formados pelos nativos do município e migrantes internos do estado ou dos outros estados do Brasil. Os migrantes internos constituem uma parcela significativa da população, e tem uma inserção melhor que os nativos em temas como emprego, cobertura previdenciária e em diversos municípios exercem o controle político. Os migrantes internacionais, quando realizaram uma migração laboral regular, pelas exigências legais, podem apresentar uma taxa de cobertura maior que outros grupos. Já os migrantes ilegais, ou sem residência permanente ou naturalização, pela sua situação irregular dificilmente obteriam cobertura do sistema previdenciário.

Os migrantes internacionais de retorno constituem um grupo que se encontra em condições precárias, muitas vezes a migração foi motivada pela procura do aceso às políticas de seguridade social. A imagem destes migrantes fracassados adquire um grande peso simbólico, o que leva a sobre-dimensionar sua presença e reforça os preconceitos enfrentados pelos migrantes de retorno. Cabe destacar aqui, que as "identidades" destes migrantes, "brasiguaios", “argentinos", "dupla-chapa", são atribuídas por terceiro e são identidades estigmatizadas que não são invocadas pelos atores, que pelo contrário preferem mimetiza-las para evitar o preconceito.

Os que realizam migração pendular internacional por motivos laborais em sua maior parte trabalham na informalidade, sem carteira de trabalho e sem cobertura previdenciária. Este movimento pendular está associado aos enclaves transnacionais e expressa a contradição entre a informalidade e flexibilização destes enclaves transnacionais e as políticas nacionais e regionais de seguridade social.

Elaboramos uma tipologia de migrantes que tem um componente dinâmico. Em última instancia existe algum ponto de contato entre a experiência do migrante, o estrangeiro, que constrói uma identidade hibrida, de ser de um lugar e do outro e a situação dos migrantes de retorno. O estrangeiro, ao retornar ao seu país descobre que a experiência da migração implicou em atravessar limites sociais. A situação do migrante de retorno, "apelidado", reflete a criação de um limite, de uma fronteira social que terá que ser atravessada. Estas identidades são produto de um processo de segmentação gerado nas fronteiras (em plural) cuja dinâmica se expressa pela manipulação das identidades. 


\section{Segmentação, mimetismo e carnavalização}

A forma mais clara de segmentação estaria dada pelas próprias fronteiras, como linhas imaginarias que dividem e ordenam à população a partir de identidades internacionais. Esta segmentação em alguns casos, como na fronteira com Argentina, está reforçada pelo aparelho de controle construído na linha de fronteira, inclusive no caso de cidades com fronteira seca como em Dionísio Cerqueira. Nas outras cidades conjugadas a linha de fronteira adquire um caráter imaginário sinalizado por diversos hitos, como marcas, monumentos ou até pela linguagem em que são escritos os anúncios. Esta segmentação tem implicâncias jurídicas na medida em que os estados nacionais se responsabilizam pelos direitos dos cidadãos que vivem do seu lado da fronteira.

Outro tipo de segmentação, hierarquicamente ordenada, é encontrada nos enclaves transnacionais. Nestes casos as identidades dos migrantes orientam relações sociais. Os comerciantes se agrupam de acordo a sua origem étnica, existindo inclusive círculos de crédito etnicamente orientados.

\footnotetext{
Anderson: - Mas tem muitos agora, né? Os indianos antes eles compravam, eles eram mais de aqueles que chegavam com dinheiro, compravam muita mercadoria com preço mais acessível, e saía vendendo nas lojas. Ganhavam uma grana sobre isso, né?! E eles são muito ricos os indianos... Lá também tem indiano, coreano, chinês, libanês, árabe, siriano, de tudo que é parte, lá do Oriente, tem de tudo que é parte, né? E eles são muito juntos, muito fechados, se uma pessoa vem de lá pra cá, eles dão uma mão pra eles montarem seu negócio.

Entrevistador: -Ah, então tem um sistema de crédito?

Anderson: -É, já... Bom, foi o que aconteceu com um libanês. Tem um amigo que trabalhou comigo lá, um libanês que a gente trabalhava junto. Falo dele, porque eu vivi junto com ele. Mas assim, como ele era parente do dono, ele cresceu mais rápido do que eu, né? Ele chegou sem dinheiro nenhum, ele não tinha um centavo. Ele chegou com o dinheiro da passagem que mandaram pra ele e ele veio. Aí, chegou aqui, fizeram tipo um empréstimo pra ele, aí todo mundo ia ajudando o cara, e o cara começou a crescer e ele começou a pagar tudo de novo. (Foz do Iguaçu).
}

Ciudad del Este, principalmente nos quarteirões na fronteira com Brasil, tem se transformado em um verdadeiro enclave transnacional, segmentado etnicamente. Na região, encontramos enclaves étnicos articulados em função de fluxos de comércio global. Estes grupos de comerciantes globais privilegiam a solidariedade étnica por sobre os mecanismos de inclusão social do estado. A atividade econômica gerada por estes enclaves transnacionais atrai migrantes brasileiros que se inserem no mercado do outro lado da fronteira. Existem aqueles que se inserem no mercado formal, como donos de lojas e trabalhadores regularizados e têm os que trabalham na informalidade. Entre estes trabalhadores irregulares têm que se diferenciar a situação daqueles que trabalham sem carteira de trabalho assinada e os que se 
desempenham como "laranjas" ou atravessadores. Cabe destacar que se a situação de laranja é moralmente reprovada, a maioria dos que passam por esta situação o fazem no início da trajetória laboral ou em momentos de crise. A condição de laranja é vista como transitória e o ideal da população é a inserção no mercado formal de trabalho.

Anderson: -Olha, é duro, é um serviço duro, um trabalha muitas horas. Se entra à sete horas e trabalha às vezes até as cinco da tarde, não tem hora de almoço, um têm um almoço de meia hora mais ou menos.

Assim... a remuneração é muito melhor que aqui,... Dependendo do local onde vai a trabalhar eles pagam melhor que aqui, eles pagam em dólares. Uns anos atrás isso era muito bom, hoje em dia não sei, não é tanto, porque o dólar se desvalorizou bastante, o movimento baixo bastante também, mas todavia compensa para muita gente.

Em vez de viver aqui para trabalhar para ganhar um salário mínimo, trabalhando 8 horas por dia, um trabalha lá dois, três vezes por semana como laranja ou passando mercadorias e acaba tirando $\mathrm{R} \$ 70, \mathrm{R} \$ 80$ por dia. Compensa, por isso ha tanto trabalho informal, tanta gente vivendo disso.

Everton: - "Não, eu estava trabalhando na Prefeitura, como estagiário não ganhava bem e não tinha carteira de trabalho, então eu suspendi a faculdade e vim para cá ganhar o duplo do que ganhava no Brasil. Mas aqui, em compensação, não tenho nenhum direito, como estagiário também não tinha. Aí eu decidi vir a trabalhar aqui.

Muitos destes trabalhadores brasileiros encontram-se em situação irregular, por não cumprirem com as condições legais para trabalhar do outro lado da fronteira. Frente à fiscalização no local de trabalho a estratégia empregada é o mimetismo.

Anderson: -Era..., geralmente era avisado antes, é muito difícil chegar algum fiscal. Geralmente quando tinha, os donos já avisavam a gente antes. Aí, você saía do local, dava uma volta. Era difícil saber quem era polícia porque eles não usavam uniforme, né? Quando eles chegavam, perguntavam sobre alguma coisa, porque geralmente eles perguntavam se a gente era paraguaio, pedia documentação. (Foz do Iguaçu)

Regina: - Eu tenho sobrinhos que trabalham lá, em comércio, normal. Então para eles possam trabalhar legalmente tiveram que fazer a dupla nacionalidade, fazer de conta que vivem lá, se não o governo não aceita. Tanto é assim que há muita gente de lá desempregada por causa disso. Então um tem que fazer todos os documentos como se fosse de lá. Nós brincávamos com um vizinho dizendo-lhe que é mais paraguaio que brasileiro, porque trabalha lá faz muito tempo. Ganha um salário decente e tem os documentos como si fosse de lá mesmo. (Regina, FI/PR)

Frente à segmentação imposta pelas fronteiras e seus reflexos sobre o acesso aos serviços públicos e direitos sociais, outra das estratégias de mimetismo passa pela hiperdocumentação. Por hiper-documentação nos referimos aos casos em que os habitantes da fronteira optam pela estratégia de registrarem-se em ambos países. Por exemplo cidadãos que 
tem certidão de nascimento no Brasil e no Paraguai, ou em Brasil e no Uruguai. Em Mato

Grosso do Sul, desde o ponto de vista dos servidores da previdência e os assistentes sociais do município, o principal problema se relaciona com a hiper-documentação. Uma parcela da população possui documentos dos dois países, como a certidão de nascimento, ou seja, as pessoas quando nascem são registradas em ambos os lados da fronteira. Estes documentos estariam sendo usados para o acesso ás políticas de seguridade social, (saúde, educação, benefícios assistenciais).

Entrevistador: - después, yo escuche comentarios en las zona de frontera no es extraño que las personas tengan documento de los dos países

Entrevistado: - no, no, exacto e... ¿y los que son acá de Pedro Juan? La mayoría tiene doble, la gran mayoría tiene... la mayoría tiene los dos documentos ¿no?

Entrevistador: - ¿pero e algo nuevo o viene de hace tiempo?

Entrevistado: - no y... ponéle que yo ahora tengo 41 años, ¿verdad?, cuando yo nací, 40 años atrás, entonces e... había mucha inestabilidad en el país, con la política y todo eso, ¿verdad?, entonces lo padres, generalmente te registraban en Paraguay y te registraban en Brasil, por las dudas ya tenía... cualquier problema. Aquí habían muchas cosas en ese tiempo ¿no?, según cuentan, es para hacer una historia, entonces por las dudas te registraban en el otro, ¿verdad?, pero acá había días a veces que no había paz y había problemas de todo eso, entonces, tipo los padres estaban previendo ya...

Entrevistador: - una estrategia para maximizar el acceso...

Entrevistado: - e... yo soy paraguayo, cuando yo tenia ya no sé cuantos años... yo toda la vida fui paraguayo... documento paraguayo la vida entera, todo del Paraguay en el colegio, en el cuartel serví en el Paraguay yo, todo, todo, y después ya cuando estaba con 15 años por ahí en la época, abro las cosas de mi mamá y encontré una partida de nacimiento mío de Brasil, uai! En 1966 se hizo. Yo nunca en la vida la usé, yo lo hice y no lo usé ¿verdad?, porque en la realidad yo estaría en infracción, pero yo nunca usé. Se hizo, pero yo nunca la usé... Cuando viajo a Brasil, miles de veces, me voy a la policía federal, saco mi permiso ya, me fui en varios lugares ya y... nunca usé ese documento, verdad, pero es un cosa, era una costumbre, antes.. tanto que... el papel estaba guardado. Hay algunos, por interés que ya van a hacer eso verdad, pero, la mayoría es porque ya se le hizo así, fue cuando nació, todo los que tienen esa e... esos, 40, 50 años toditos tienen, porque en esa época, habían muchos problemas acá en el país e, entonces, previendo eso, tal vez los padres hayan hecho eso. (Pedro Juan Caballero, Py.)

A situação na fronteira com Uruguai é diferente da situação com Argentina. Em Barra do Quarai, por uma questão de distâncias, o hospital mais próximo do lado brasileiro fica a 70 $\mathrm{km}$, muitos dos partos são realizados do lado uruguaio e registrados no Brasil, quando funciona o cartório na cidade. Esta dinâmica, que adquire proporções maiores em outros municípios da fronteira gerou o que na região se denomina "dupla-chapa", que se refere aos brasileiros ou uruguaios que tem registro em ambos os lados da fronteira.

Entrevistador: - Uma coisa que escutei aí em Uruguaiana que falam que o hospital mais próximo é o do Uruguai. E as mulheres que estão para parir vão parir lá do outro lado.

Danilo: - É, são 72 quilômetros de Barra a Uruguaiana e muitas vezes não dá tempo, o hospital mais perto é de União, tem sido atendido o pessoal daqui da Barra.

Entrevistador: - Mas tem problema para ser atendido? 
Danilo: - Não, o único problema que gera é quando as mulheres grávidas têm o filho lá é no registrar aqui no Brasil. Que aí está dando complicação, que eles não aceitam o atestado de nascido vivo lá, aqui. Isso gera um tipo de...aí tem que entrar com um outro recurso para poder validar aqui no Brasil. Mas quanto a isso aí de ser atendido lá, não tem problema.

Entrevistador: - O que nasce lá, é uruguaio ou é brasileiro?

Danilo: -É, já tem uma lei agora que obriga eles registrarem lá e aqui. Aí quando a criança atingir a sua maioridade vai optar por a sua nacionalidade ou vai escolher ser uruguaio ou brasileiro.

Entrevistador: - Aconteceu com você isso?

Danilo: - Não, eu sou filho de mãe uruguaia e de pai brasileiro, nasci aqui mesmo. Tenho um pé lá também.

Estas estratégias são realizadas como jeitinho, mais também como forma de maximizar os benefícios em ambos os lados da fronteira. Uma situação diferente é a enfrentada pelos migrantes de retorno. A situação de discriminação enfrentada por estes migrantes se faz evidente pelos apelidos que recebem ao longo da fronteira: "Brasiguaios", "Argentinos", "dupla-chapa”.

No estado do Paraná a principal dificuldade, assinalada pelos funcionários da previdência e assistentes sociais do município, é a inclusão nos serviços de seguridade social dos migrantes de retorno, conhecidos como "brasiguaios". Com efeito, a estrutura social da região sofreu o duplo impacto da construção de um grande projeto com a represa de Itaipu. Este empreendimento, por um lado atraiu numerosos migrantes internos, mobilizados pelo engajamento no grande projeto como força de trabalho, ao mesmo tempo que o enchimento do reservatório implicou a inundação de uma extensa faixa de território e provocou o êxodo de parte desta população rural. Uma parcela considerável desta recebeu indenização pelas terras alagadas e, motivadas pelo preço da terra no Paraguai, migrou para a zona rural do país vizinho. Outros contingentes se somaram a esta corrente migratória, que atraiu também moradores da região sul e sudeste do Brasil. Os cálculos oficiais do censo de Paraguai falam de um contingente de 100.000 brasileiros. Já os dados da igreja e dos movimentos sociais apontam para uma cifra acima dos 300.000 brasiguaios. No debate eleitoral no Paraguai se invoca a cifra de 800.000 elevando o numero destes cidadãos híbridos.

Paulo: - Os brasiguaios se concentram lá em Santa Tereza, seria bom se vocês fossem lá, na Vila Paraguaia, pra poder ver a situação desse pessoal né. Porque tudo é bem precário. Eles vão emendando casa na outra e vão se ajeitando, é verdade.

Maria: - Nós não temos favela aqui em Itaipulândia, graças a deus, né, então estão iniciando assim. E o prefeito investe, tira isso e daqui a pouco vem mais um, uma leva e vão construindo casinhas e vão se ajeitando.

Entrevistador: - A senhora falou uma leva, eles vem em grupos mesmo?

Maria: - É, porque vem a parentade né?

Paulo: - É um puxa, é uma corrente, um puxa o outro. Amigo, colega, parente, vai vindo então a corrente, vamos pra lá, vamos pra lá que lá a saúde é de graça, a educação é de graça. O prefeito daqui então nem quer mais, então ele deu uma brecada, ele deu uma cortada, começou a cobrar uns impostos, umas coisinhas 
básica da população, então eles pararam, disseram, não, mudou a coisa, já não é mais assim, então por isso que deu uma parada.

Maria: - Porque eles vêem de lá. Eles não têm uma mentalidade de crescer, quer viver a custo, não vê pra frente. Então eles vêem aqui, faze um casal, trabalhar por uma cesta básica, bom ai pronto, bota o filho na escola, vão ao posto de saúde tem a consulta, tem o medicamento, pra eles ta bom.

Entrevistador: - Recebe o bolsa-família?

Maria: - É, isso, isso.

Paulo: - O bolsa-família eles não entra porque num tem documento brasileiro.

(Maria Macedo e Paulo Carvalho, Promoção social de Itaipulândia, Paraná).

No estado de Santa Catarina, não temos nenhum grande município na zona de fronteira. Os principais pólos do estado são Florianópolis, capital do estado e Chapecó, onde se localiza a gerência do INSS responsável pelo atendimento nos municípios da zona de fronteira. Os municípios visitados têm uma economia baseada na agricultura de pequena propriedade. Neste caso o grupo com dificuldades de acesso à seguridade social é o dos "argentinos", como são denominados na região os migrantes de retorno do país vizinho ou os migrantes que residindo no país vizinho vem a Brasil em procura de atenção médica, medicamentos, educação o benefícios da assistência social.

Entrevistador: - "Não porque a assistente social da saúde, da Secretária da Saúde, falou que tem casos de "argentinos" que vem aqui passam a residência pra ter atendimento à saúde, alugam uma casa durante dois meses e depois voltam. Para mim não ficou claro se aquilo que ela chamou de argentinos eram brasileiros que tinham migrado e voltavam ou eram argentinos que vinham, sei lá argentinos da zona rural que se instalavam aqui..."

Assistente social: — É, geralmente assim, o, quando ela fala de "argentino", eles não são argentinos mesmo, eles são brasileiros, só que eles vão pra lá e depois eles acabam voltando. Pelo fato de eles serem brasileiros e terem documentos aqui, eles vão na Argentina, eles não tem a assistência que eles precisam, porque é outro país, aí eles acabam retornando aqui, pedindo ajuda pra nós. Muitos residem lá por um período de tempo vem pra cá, pra ver. Quando ela fala de "argentinos" eles não são argentinos, eles são brasileiros, só que eles vão pra lá morar justamente pelo que eu falei e eles acabam voltando porque lá eles não tem a assistência que eles realmente precisam.

Assim, nós conhecemos um pouco a realidade deles da cidade mais próxima aqui que é Bernardo de Irigoyen. A gente já teve no hospital lá, nós já tivemos visitando a prefeitura, tudo e assim, a estrutura que eles fornecem ainda é mais precária que aqui de Dionísio. Então o que acontece, são brasileiros que quando eles precisam de alguma coisa da saúde eles vêm pra cá. A saúde aqui fornece um pouco mais de apoio, subsídios, estrutura, só que também tem aqueles "argentinos" que vem pra cá, às vezes, e tem que provar residência aqui, alguma coisa nesse sentido, pra poder ter um atendimento aqui. Também, só que assim, quando ele é argentino mesmo, porque a gente sempre pede a documentação, quando ele apresenta uma documentação Argentina a gente orienta a retornar pra lá, porque a gente aqui, nós é outro país né, nós procuramos atender as pessoas aqui mesmo do nosso país, né, dificilmente é atendido alguém que é naturalizado argentino... (Claudiane, Secretaria de Promoção Social, Dionísio Cerqueira, SC)

Esta situação se repete também em municípios de Rio Grande do Sul em que predomina a agricultura em regime de subsistência. 
Assistente social: - É, alguns argentinos. O que mais tem são brasileiros que moraram bastante tempo na Argentina e que retornam para cá, principalmente quando completam sessenta e cinco anos de idade, em função da aposentadoria, do benefício assistencial. Então eles vivem na Argentina por muito tempo e aí retornam ao Brasil para receber o benefício. E aí, uns ficam aqui, outros vêm todo mês receber o benefício e voltam a morar, mas são mais raros os casos. Então o que acontece, que nós temos aqui, é isso. Mas de imigrantes que vêm morar aqui não é muito comum. (Porto Xavier, RS, Br.)

A principal dificuldade enfrentada pelos funcionários do INSS é com os "duplachapa", como são designados na região os que têm documentos de ambos países. Devido à interpenetração da população uruguaia e brasileira nesta cidade administrada por dois estados, uma das irregularidades identificada frequentemente é a de cidadãos que pleiteiam os benefícios assistenciais em duplicidade, nos dois países. Estes casos puderam ser detectados graças à colaboração, informal, entre os funcionários do INSS e do BPS. A colaboração translocal se apresenta como uma forma de detectar fraudes mais eficaz que a desconfiança sistemática.

Vilson: -A dupla chapa é com relação ao Uruguai. Aqui na Argentina, mesmo na divisa com a Argentina, nós não temos. A dupla chapa aí atinge muito é Santana do Livramento e Quaraí. São os dois municípios bem na fronteira. Quaraí também tem a ponte, e Santana do Livramento que é fronteira seca, vamos dizer assim, só uma rua. Lá em Santana do Livramento tem muito beneficiário que recebe, inclusive irregularmente, benefícios dos dois lados. É irregular, então é muito difícil de descobrir. A gente tem um colega lá, o chefe da agência, que faz as pesquisas em função dessa situação. Ele pesquisa do outro lado e felizmente, lá eles têm um bom entrosamento, o INSS, a Previdência Social no Brasil, com o Banco de Previsión Social, BPS, no caso, do Uruguai. Então, qualquer dúvida, a gente vai lá, fala com o colega do outro lado e descobre essa situação. (Uruguaiana, RS, Br.)

Frente à situação de discriminação enfrentada, tanto pelos migrantes de retorno, como pelos migrantes dos países vizinhos em situação irregular, a estratégia empregada consiste mais uma vez no mimetismo. Na voz de uma migrante indocumentada de Argentina:

\footnotetext{
Entrevistador: - E quando morava na Argentina, teu marido enfrentava esse mesmo problema... não?

Rosa: - Si.

Entrevistador: - Qual era o problema que enfrentava lá?

Rosa: - El problema de él, por ejemplo, para consultar, si no tenía documento no era consultado para un trabajo bueno, así en encharcado, tampoco no podía y... no podía divulgar que era brasilero tampoco. O sea que yo vivo tranquila, nadie me dice nada, no sé. Todos saben que yo soy argentina. Solo que allá en Argentina no pude decir que es brasilero, porque enseguida vienen los milicos, te dicen que tienen que desocuparnos, o si tienen los papeles, y ahí nos tenia que andar así, no podíamos decir nada. En Argentina, como no tenían papeles, los chicos no iban a escuela, no tenían documento argentino. Ya los mayores tenían brasilero, pero nosotros no podía divulgar porque si no..
}

Entrevistador: - E como fazia para não divulgar?

Rosa: - Y, si no hablábamos no incomodaban para nada. (Guaraciaba, SC, Br.). 
Como assinalamos ao falar sobre a segmentação criada pelas fronteiras, este processo é tensional e instável, como o revelam as diversas estratégias de mimetismo empregadas pelos atores que as atravessam. Frente a estas tensões se revela a outra dinâmica, contraposta ao mimetismo, que consiste na carnavalização das formas. Esta carnavalização das formas se expressa quando as tensões são canalizadas por confrontos esportivos, como jogos de futebol ou por confrontos motivados pela dinâmica dos fluxos através das fronteiras.

Delmar: - É, cada vez que tem jogo do Brasil com o Uruguai tem que fechar ali, pelo menos na linha divisória e mandar fazer, passar uma quadra para dentro, uma quadra para cá porque mesmo assim eles se provocam tanto. Porque vamos sempre ganhar do Uruguai. (Santana do Livramento)

A forte relação translocal entre Ciudad del Este e Foz do Iguaçu se faz evidente pelo numero dos que realizam migração pendular e se inserem nos diferentes nichos deste mercado transnacional. A dinâmica de ambas as cidade é interdependente e sensível a decisões tomadas a nível internacional. A população brasileira da região é favorável a uma liberação comercial mais ampla, uma vez que parte importante da atividade econômica depende do comércio transnacional em Ciudad del Este. As medidas de restrição ao comércio, como uma maior fiscalização, resultaram em conflitos orientados pelas identidades performáticamente realizados na ponte, que conecta e divide ambas as cidades. A carnavalização das formas, a atuação das identidades nestes contextos de tensão orienta as relações sociais de acordo com as identidades, em sistemas interétnicos que interatuam cotidianamente fortemente entrelaçados.

"Já aconteceu muito quando tem aquelas brigas ali na ponte de fecharem a ponte, aquilo ali, dá muita polícia, aqueles tiros de borracha, não sei como que eles falam lá. Então é tudo difícil de repente, você fala para o filho que vai chegar tal hora, e passa tal hora e você não chega. Sabe é tudo assim muito difícil nessa parte ali para eles. E é no que eles estão conseguindo sobreviver disso aí.

Acabando com isso, aí melhora para o governo. Igual eles querem que seja uma cidade só turística e tal, mas aí tem que fazer alguma coisa para o povo daqui se sentir motivado, trabalhando e com salário, com carteira assinada. (...) (Regina, Foz do Iguaçu)". 


\section{Mercosul, previdência e depois.}

As percepções sobre o Mercosul registradas nas diferentes localidades da fronteira não são positivas. O imaginário de integração mobilizado pelo Mercosul como projeto, e o impacto na dinâmica social da zona de fronteiras deixa transparecer contradições entre a formulação ideal, desde os formuladores de políticas, e a situação empírica verificada nas áreas de fronteiras.

A percepção comum entre os entrevistados é que o Mercosul passa por cima, eles vêem a circulação de mercancias nos caminhões que circulam através das fronteiras. Quando as fronteiras operavam como tampões que travavam a circulação de mercadorias, tinham gerado um setor de despachantes e depósitos que se viu desmontado com a nova dinâmica. Com a implementação do Mercosul os produtos são inspecionados na saída e na chegada no porto seco. Na zona rural, os casos de febre aftosa intensificaram os controles fito-sanitários e dificultaram a circulação de gado entre as localidades da fronteira e as condições climáticas se somaram a outros fatores para provocar uma crise do setor agrário na região sul do Brasil.

Uma das críticas realizadas pelos pequenos produtores é que o Mercosul funciona só para as pessoas jurídicas e que os pequenos produtores agrícolas, como pessoas físicas não podem comprar insumos nem vender seus produtos do outro lado da fronteira.

O Mercosul enfrenta outras contradições decorrentes dos fluxos globais de comércio que se concentra nas principais cidades da região de fronteira. Impulsionadas por políticas de isenção fiscal, pelas diferenças que ainda subsistem na TEC ou pelo contrabando, Pedro Juan Caballero, Ciudad del Este e Rivera têm se transformado em importantes centros comerciais de venda de produtos importados (extra-zona), com um mercado orientado para os consumidores brasileiros.

Este encontro dos fluxos do comércio local/global com a dinâmica do Mercosul gera contradições. Pela lógica do Mercosul estes produtos produzidos por terceiros países são produtos extra-bloco. A lógica do Mercosul leva a uma maior liberalização do comércio dos produtos intra-blocos e a uma maior fiscalização, em princípio, para a circulação dos produtos extra-zona.

Esta diferença no tratamento aos produtos produzidos no interior do bloco leva a sensação de que só os produtos brasileiros, país com maior parque industrial, são os que circulam livremente pelas fronteiras. Esta percepção leva a reclamos por uma maior liberalização do comércio, sem distinção entre produtos intra-zona e extra-zona. Frente à fiscalização nas áreas de fronteira, estes reclamos se verbalizam em expressões como: o 
"Mercosul favorece o Brasil, o que produz Paraguai? Paraguai produz na China" ou "O Mercosul não é livre comércio?" ditas por comerciantes brasileiros que realizam migração pendular.

Este movimento comercial transnacional gera um numero importante de empregos, inclusive para cidadãos brasileiros que realizam migração pendular para trabalhar no país vizinho. O principal problema identificado, desde o ponto de vista das políticas previdenciárias se relaciona com este importante grupo que realiza migração pendular, na medida em que a maior parte trabalha na informalidade, sem carteira de trabalho assinada e sem realizar contribuições para o sistema previdenciário de nenhum dos dois países.

Por outro lado, nos últimos anos, a região enfrentou um sigiloso movimento de migração rural/rural internacional. Estes migrantes, frente a discriminação enfrentada tentam se mimetizar para não chamar a atenção. A inclusão deste grupo de migrantes de retorno é uma das dificuldades apontadas recorrentemente pelos funcionários das agências da Previdência Social (APS) nas cidades de fronteira e pelos assistentes sociais dos municípios visitados.

Cabe destacar que, apesar da difícil quantificação, este grupo em termos quantitativos é menor que os que realizam migração pendular nas principais cidades. Estes migrantes de retorno escolhem para fixar sua residência as localidades de origem ou se estabelecem nos municípios da faixa de fronteira pela solidariedade de amigos ou familiares. Existem casos em que migrantes que moram do outro lado da fronteira, atravessam o limite para terem acesso à saúde ou aos benefícios assistenciais como o LOAS-idoso, mas é impossível estabelecer com que freqüência acontecem estas situações.

A desconfiança sobre o lugar de residência dos migrantes de retorno e os casos de hiper-documentação levam a que os funcionários desenvolvam uma desconfiança sistemática dirigida a aqueles que apresentam algum vestígio de sotaque hispânico na suas falas, sejam migrantes de retorno ou trabalhadores estrangeiros legalmente estabelecidos. Esta suspicácia termina gerando uma situação em que estes migrantes são fiscalizados com maior atenção.

Frente a estas contradições, a percepção generalizada que existe nas cidades da zona de fronteira, é que o Mercosul foi feito para os empresários e para o trabalhador formal dos grandes centros. Na zona de fronteira a percepção é que não são beneficiados pelo processo de integração e que o Mercosul "só existe nos papéis". Os diferentes tipos de visto em vigência com os diferentes países reforça essa percepção de que o Mercosul ainda está longe de uma efetiva livre circulação de trabalhadores, ou para ser mais amplo, dos cidadãos dos 
países do Mercosul. No âmbito do Acordo Multilateral de Seguridade Social é importante desenvolver e/ou fortalecer políticas sociais nas áreas de fronteira, onde a população muitas vezes possui livre acesso ao mercado de trabalho e quase nenhuma proteção social. Devemos esperar que estes diversos tipos de migrantes se adaptem à legislação vigente ou devemos adaptar a legislação e implementar políticas para incluir estes migrantes de retorno, pendulares e estrangeiros que vivem nas fronteiras?

Na línea imaginária da fronteira se constroem múltiplas fronteiras: identitárias, jurídicas, alfandegárias. Se a fronteira ao delimitar separa, pela contigüidade põe em contato. As fronteiras longe de ser intransponíveis, são permeáveis, estão envolvidas por uma dinâmica translocal que entrelaça ambos lados. Como não poderia deixar de ser, os habitantes e particularmente aqueles que trabalham nelas participam destes sistemas híbridos.

Os trabalhadores nas fronteiras, com suas migrações, refletem também os limites das políticas de seguridade social. Estas migrações na fronteira, das que participam estrangeiros, migrantes de retorno, migrantes pendulares, são migrações laborais, muitas vezes à margem do sistema formal de trabalho. O Acordo de seguridade social foi pensado a partir do mundo do trabalho formal, trabalhadores urbanos, documentados, com aportes previdenciários nos diferentes países do bloco. Existem alguns casos que se encaixam neste perfil, mais estão longe de constituir-se como casos típicos. Pelo contrario, os testemunhos levantados apresentam um perfil de população diferente, onde até a documentação pode resultar problemática. Os migrantes típicos destas fronteiras são os migrantes pendulares, de retorno, os não documentados.

Documentos. Ao longo das fronteiras observamos os dois extremos das dificuldades com a documentação. Por um lado, na população das fronteiras com Paraguai e com Uruguai observamos o problema da hiper-documentação. Por outro lado, em alguns dos casos de migrantes de retorno, observamos a falta de documentação e as dificuldades, por parte da população rural, de cumprir com os requisitos cartoriais, como vistos e traduções juramentadas, para regularizar sua situação.

Outro dos pontos abordados é o trabalho nas áreas de fronteira, especialmente o trabalho dos que realizam migração pendular. Nestes casos combinam- se uma baixa formalização das relações de trabalho, com a exploração de enclaves transnacionais. Apesar da contradição entre a lógica da regionalização e a lógica da globalização, nada impede que estes enclaves formalizem as relações de trabalho. A extensão do direito ao trabalho e a eliminação de vistos de trabalho fronteiriços podem colaborar com a regularização da situação 
de milhares de trabalhadores que realizam migração pendular na fronteira. A formalização das relações de trabalho é a porta de entrada para a inclusão na política previdenciária.

No plano regional, o Mercosul realizou importantes avanços em um lapso relativamente curto de tempo. Com o acordo de seguridade social se realizou um avanço significativo para a extensão dos direitos previdenciários para os trabalhadores, formais, migrantes, urbanos. Estes avanços incluem o reconhecimento dos aportes previdenciários nos diferentes países do bloco. Este acordo abarca os benefícios que poderíamos enquadrar como bismarkianos, ou contributivos. Ao analisar a distribuição dos benefícios observamos uma importante presença de benefícios beveridgiano, o não-bismarkianos (Schwarzer 2000). Estes benefícios previdenciários, como a aposentadoria para o trabalhador rural, ou benefícios assistenciais, como a LOAS, não estão contemplados no Tratado.

Os sistemas bismarkianos, baseados na contribuição tripartite, na solidariedade intergeracional, e na proporcionalidade entre o salário e o benefício, foram formulados no contexto da industrialização crescente e urbanização acelerada da Alemanha de finais do século XIX. Este modelo orientou a estruturação dos sistemas previdenciários nos países do cone sul. As políticas beveridgianas surgiram no cenário do fim da segunda guerra mundial e da formulação do Welfare State. Os benefícios beveridgianos são financiados a partir das fontes do tesouro e não existe proporcionalidade com o salário nem necessidade de aportes prévios.

Os processos de integração para ter êxito tem que superar o dilema, colocado por Habermas (1989, 1997), em termos de nacionalismos de exclusão ou patriotismo da Constituição. Os episódios de carnavalização das identidades nos momentos de tensão não deixam de ser uma tendência dos nacionalismos de exclusão. Para consolidar e aprofundar o processo de integração seria recomendável avançar na formulação de uma Carta Social. A Carta Social Européia, entre outros pontos estabelece o direito ao trabalho no mercado comum e garante o acesso à seguridade social para o trabalhador migrante e sua família. 


\section{Bibliografia}

Albuquerque, José Lindomar C. 2005. Fronteiras em movimento e identidades nacionais: a imigração brasileira no Paraguai. Tese de Doutorado em Sociologia. Programa de Pós-graduação em Sociologia da UFC, Fortaleza_Ce. [ defesa 10/10/2005].

Alvarez, Gabriel, O. 1995. Los Límites de lo transnacional: Brasil y el Mercosur. Una aproximación antropológica a los procesos de integración. Série Antropologia, Nro. 195. Departamento de Antropología. Brasília: Universidade de Brasília.

Alvarez, Gabriel, O. 1995. MERCOSUR Ritual, Políticos y diplomáticos en la política de integración del Cono Sul. Tese de Doutorado em Antropología. Programa de Pós-graduação em Antropologia Social. Departamento de Antropologia. Universidade de Brasília.

Alvarez, Roberto R. 1995. "The Mexican - US Broder: The Making of an Anthropology of Borderlands". Annual Review Anthropology. 24:447-70.

Appadurai, 1994. "Disjunção e diferença na economía cultural global" in: Featherstone, 1994. Cultura Global. Nacionalismo, globalização e modernidade. Ed. Vozes, Petrópolis, Rio de Janeiro.

Azambuja, Marcos Castrioto, 1994. "O Relacionamento Brasil - Argentina: de Rivais a Sócios". In: Fonseca Junior, S. Nabuco de Castro, S.H. 1994.

Baeninger, R. e Leoncy, C. 2001. "Perfil dos estrangeiros no Brasil segundo autorizações de trabalho e registros de entradas e saídas" in: Castro, Mary Garcia (coord.) Migrações Internacionais, contribuições para políticas. Brasília: CNPD

Bandeira, Luiz Alberto, Moniz. 1996. "Políticas y relaciones internacionales en el Mercosur". Ciclos, año VI, Vol. VI, Nro 11.

Barth, Fredrik. In: Lask Tomke 2000 (org.) O guru, o iniciador e outras variações antropológicas. Rio de Janeiro: contra capa.

Baylis, John y Smith, Steve (ed.), 1997. The globalization of World Politics. London: Oxford University Press.

Borba Casella, Paulo, 1996. Mercosul. Exigências e perspectivas. Integração e consolidação de espaço econômico (1995-2001-2006). Editora LTr, São Paulo.

Butler, Fiona, 1997. "Regionalism and Integration" in: Baylis J. Smith, S. The globalization of World Politics. Oxford University Press. London.

Bustamante, 1983. "Maquilladoras: a new face of international capitalism os México's Northern Frontier", in: June Nash \& María Fernandez-Kelly (orgs) Women, men and the international division of labours. New York: States University of New York.

Cardoso de Oliveira, R. 1976. Identidade, etnia e estrutura social. São Paulo: Pioneira.

Cardoso de Oliveira, R. 1996. O índio e mundo dos brancos. São Paulo: Editora da UNICAMP.

García Canclini, Nestor, 1995. Consumidores y Ciudadanos. Conflictos multiculturales de la globalización. Ed. Grijalbo. México.

García Canclini, Nestor, (coord.), 1996. Culturas en Globalización. América Latina - Europa Estados Unidos: libre comércio e integración. Nueva Sociedad. Venezuela.

García Canclini, Nestor, 1997. Culturas Híbridas. Edusp, São Paulo.

Geronini, Eduardo, 2005. "Admisión, contratación y protección de trabajadores migrantes. Panorama de la legislación y la práctica nacionales de Argentina, Bolivia, Brasil, Chile, Colombia, Ecuador, España, Perú, Portugal y Uruguay”. Estudios sobre migraciones internacionales OIT, Nro 70. OIT: Ginebra

Harvey, David, 1993. Condição Pós-Moderna. Uma pesquisa sobre as origens da mudança cultural. Ed. Loyola. São Paulo. 
Hirst, Monica, 1996. "Pontos de Reflexão sobre a Dimensão Socio-Político-Cultural do Mercosul". In: FUNAG, 1997. Mercosul e a Integração Sul-Americana: Mais do que a Economia. Encontro de Culturas. FUNAG, Brasília.

Marcano, Elvia Jimenez, 1996. La consrucción de espacios sociales transfronterisos en Santa Helena de Uairem (Venezuela) y Villa Pacaraima (Brasil). Tese de Doutorado. Programa de Doutorado conjunto FLACSO/UnB em Estudos comparativos sobre América Latina e o Caribe. Universidade de Brasília, Brasília.

Margolis, 1994. Little Brazil: an ethnography of Braziliam inmigrant in New York city. Princeton: Princeton University Press.

Marques, Renato L.R. 1997. "O Nacional versus comunitário no Mercosul - A questão dos fundos e o estagio atual do processo de integração". Boletim de Integração Latino-Americana Nro. 20, MRE / SGIE / GETEC. Brasília.

Oman, Charles, 1994. "Globalisation et régionalisation: quels enjeux pour les pays en développement?" Études du Centre de Développement de l’OCDE, Paris.

Ribeiro, Gustavo Lins, 1994. "Imobilização da força de trabalho. Considerações sobre os modos de expansão concentrada e difusa". Série Antropologia, Nro 172. Departamento de Antropologia, Universidade de Brasília, Brasília.

Santos, Bonaventura de Sousa, 1995. Pela mão de Alice. O social e o político na pós-modernidade. São Paulo: Cortez Editora

Sant'ana, Marcilio Ribeiro de ... 2001. "Livre circulação de trabalhadores no Mercosul?" in: Castro, Mary Garcia (coord.) Migrações Internacionais, contribuições para políticas. Brasília: CNPD

Schwarzer, Helmut, 2000, "Paradigmas de Previdência Social Rural: um panorama da experiência internacional" Texto para discussão nro. 767. Brasília: Ipea. Disponível em http://www.ipea.gov.br

Velho, Otavio Guilherme, 1976. Capitalismo autoritário e campesinato: Um estudo comparativo a partir da fronteira em movimento. São Paulo: Difel-Difusao Editorial.

Vigevani, Tullo. 1998. "Globalização e Política: ampliação ou crise da democracia?" in Dowbor, L. Ianni, O. y Resende, P.E.A.(org.). Desafios da Globalização. Petrópolis, Rio de Janeiro : Editora Vozes.

Wagner, C. 1998. Brasiguaios, homens sem terra. Petropolis: Vozes

Wolf, Eric, 1994. Europa y la gente sin historia. Fondo de Cultura Económica. México.

Wolf, Eric, 2003. "Nacionalismo camponês em um vale dos Alpes", in: Bela Feldman-Bianco e Gustavo Lins Ribeiro, Antropologia e Poder. Contribuições de Eric R. Wolf. Brasília: Editora da Universidade de Brasília: São Paulo: Editora Unicamp. 